\title{
IMPACT OF PERSONAL ORIENTATIONS ON ATTITUDES TO DIVERSITY AND CIVIC SOCIAL-POLITICAL ACTIVENESS
}

\author{
Yolanda Zografova \\ Bulgarian Academy of Sciences, Bulgaria \\ E-mail: zografova@abv.bg
}

\begin{abstract}
The dynamically ongoing processes of integration are among the crucial premises for the development of contemporary interpersonal, intergroup and cross-cultural relations, attitudes, conflicts and more. The research problem here directs to an analysis, based on ESS data collected in 8 countries, rounds 2006 and 2008, on the extent to which Europeans' personal orientations significantly influence the attitudes towards ethno-national diversity, in this case, towards two social groups: immigrants coming from poorer countries outside Europe and people with different sexual orientation. Furthermore, the influence of the same factors on the civic activeness and involvement in the social-political processes has been followed. Through regressive analysis the important effect of the co-otherness orientation (a concept developed by Sicakkan, 2003), the orientation to success and traditionalism on all included dependent variables has been proved. The expectations for predicting effects of the three personal orientations have been confirmed regarding the civic involvement and tolerance to diversity. Simultaneously the necessity of working EU politics to deal with the risks of emerging negative attitudes has been pointed out in relation to the broad immigrant and refugee wave to European countries.
\end{abstract}

Key words: attitudes towards immigrants, civic activeness, co-otherness.

\section{I ntroduction}

The processes of integration in contemporary Europe are a powerful factor that determines a high extent the development of new forms of intergroup behaviour and intergroup relationships. There are undergoing changes on a collective, as well as on a personal level. Individuals face opportunities of mobility and diverse contacts, interaction with persons, groups, organizations. Thus, a path uncovers to transfer behaviour models, social values, European values forming similar social representations among Europeans. Processes of identification are being dynamized by the increasing multiple and diverse social groups that individuals affiliate to; memberships, therefore, be it overlapping or independent, are a characteristic feature of contemporary individuals. There are processes of identification of the personality with new social groups, communities and nations. They also premise the acceptance of trans-European values and behavior models. On the other hand, the phenomena of inter-groups relations, perceptions and stereotypes are dependent both on the history of these relations and on the specific features of the corresponding communities, nations, ethnic groups. Person does not only affiliate with and commits to particular social groups, but personal behaviour and specific perceptions of the external groups are influenced to a great extent by the imaginable or real membership in the groups (Tajfel, 1981; Turner, 1984). 
Based on the social-cognitive approach, it can be stated that the more the categories into which we represent other persons or groups broaden, the more we liberalize our attitudes towards other people, the easier we perceive other persons' attitudes towards us, as well as other persons, groups, communities, and nations as co-others. The particular expression of such enlargement is the reception of immigrants from various states, having different characteristics as equal representatives and participants in the same public spheres. Regardless of the opening of international boundaries and the increased mobility, however, national identity remains a persistent connecting commune phenomenon. "Modern history is construed first and foremost as an aggregate of national histories" (Calhoun, 2003, p.231) However, again Calhoun suggests that "even if the positive, monolithic identity is a form of violation against the otherness, the absolute diversity is also a form of violation against intersubjectiveness and especially against human will a bridge to be construed above the abyss among people, traditions, cultures" (ibid, p.137). Indeed, absolutizing the distinction between otherness and identity or between supra-nationality and nation would result in amorphousness of the "image" of the contemporary civic society, just as absolutizing the opposite would lead to development and even ethnocentrism at certain points. It turns out that the process of collective identity formation shall be completed successfully, so that a European community is developed by those European Union citizens who support common values, norms, rules, which will enhance the European public sphere; on the other hand, a ground to develop a collective European identity barely exists and multiple difficulties and barriers to form one, are being indicated. "The mass basis is weak as is the collective identity" (Eriksen, 2005, p. 350). A ground path to building common values and identity passes through the common space for discussion where every person shall have the right to express her thoughts in the "pan-European discourse" - in one single European sphere - but it seems that the important point here is that everyone to have the freedom and the willingness to involve in the important issues of the Euro-integration processes. The relation between the civic active involvement in the political processes of integration and the collective European identity is accepted as regular and requiring a profound analysis and representative research (Immerfall, Boehnke, Baier, 2010). According to the approach suggested by Brewer, the concept social identity complexity allows us to pose the issue of identity of the European citizens of today from the viewpoint of affluence of identifications they commit to and internalize (Brewer\&Pierce, 2005). This concept creates the possibility to include the idea of co-otherness as a main factor or a variable amidst the significant orientations of values to establish ways to broaden intergroup, intercultural tolerant images and relations. "The "co-other" is not a physical reality. It is a state of mind that enables individuals to see themselves as "just another other", i.e., as a third person who is different both from the self and from the concrete others surrounding the self" (Sicakkan, 2008, p. 8). Co-otherness also involves another individual characteristic - a mental mobility between different references of identification - e.g., between one's own and other people's ethnic, religious, gender, territorial, sexual etc. belongings (Ibid).

Partial intersection /overlapping of different identities and the extent to which individuals succeed to perceive their affiliations is not limited to one category or in-group. "When an individual acknowledges, and accepts, the non-overlapping memberships of her multiple in-groups, her subjective identity structure is both more inclusive and more complex."(Brewer\&Pierce, 2005, p. 429) Intercultural representations, openness toward others would develop and widen on such a basis. The research question and the goal being set this paper is to scrutinize how personal orientations, including the religiousness of the respondents from European countries, influence the acceptance of diversity, expressed in attitudes towards immigrants, towards people with a different sexual orientation and how these orientations influence the sociopolitical activeness and Eurointegration of citizens in Europe.

\section{Methodology of Research}

A part of a broad comparative analysis* of ESS data in 2006 and 2008 rounds for 8 countries is presented here (see Zografova, 2011 for details).

* This analysis is a part of research, conducted within an Integrative project "Eurosphere", funded by the 6FP of the EC, coordinated by prof. Hakan Sicakkan, University of Bergen. 
The selected countries are Belgium, Bulgaria, Denmark, Norway, Estonia, Germany, Spain and Great Britain, total number of respondents for 2006 - 15156; for 2008 - 15592 respondents.

The attitudes towards immigrants, towards people with different sexual orientation, the citizens' participation in the public sphere, explored in the dynamics of phenomena, are measured during the selected two ESS rounds. Even though the period is too short to expect significant alterations in the influence of the included attitudes, it can be stated that even if there are no fundamental modifications, the tendencies are quite important because of the shorter terms of crucial changes, happening in EU. But due to the fact that stereotypes, value orientations and other psychic features are the slowest changed phenomena, significant dynamics could not be expected, especially within a period of two or three years.

As predicting factors regarding the attitudes toward others and the involvement of citizens in political processes, through the current work the outlined personal orientations in three factors based on ESS data have been referred to. These factors have been outlined in previous analyses of ESS data (Sicakkan and Zografova, 2009) Three factors were outlined and they received the following working titles: Co-other Orientation /comprising items from Universalism and Benevolence/, Traditionalism/ Community- centred Orientation /comprising items from Tradition, Security and Conformity/ and Orientation toward success/Self-centred Orientation/comprising items from Self-Direction, Stimulation, Hedonism, Achievement and Power/ (see Schwartz, 2012). The factor decision correlates with the few items corresponding to the values, in view of the prefered short and partly modified version of Schwartz's PVQ in the ESS. This leads to a combination of adjacent values (ibid.) and the working titles reflect the common patterns of types of values orientations.

Other important dependent variables are: trust in the European Parliament, measured with the question "How much you personally trust the European Parliament?"; and the attitude to go further with the integration in Europe with the question: "Now thinking about the European Union, some say European unification should go further. Others say it has already gone too far... what number on the scale best describes your position? The person answer using a scale from "1 -Unification has already gone too far" to "10 - Unification should go further".

\section{Influence of the Personal Orientations on Attitudes towards Diverse Groups, as Well as on Civic Activeness and I nvolvement in European I ntegration Processes}

Regression analysis has been conducted on the influence of co-otherness, traditionalism, orientation towards the success, level of religiousness on attitudes towards immigrants, towards people with different sexual orientation, towards the EU integration, the trust in the European Parliament, and activeness and participation in different political activities. The data analysis shows that the cootherness orientation is outlined as an important predictor and with the most significant role compared to all included dependent variables, namely - a continuing Euro-integration, the immigrants coming from poorer countries, people with different sexual orientation. Co-otherness also exerts a positive influence on the attitude of trust towards the European Parliament, as well as on the socio-political activeness of the European citizens /see Table 1, Table 2, Table 3/.

Table 1. Influence of personal orientations on the attitudes towards the Eurointegration and on the acceptance of immigrants.

\begin{tabular}{|c|c|c|c|c|c|c|c|}
\hline $\begin{array}{l}\text { ESS } \\
\text { round }\end{array}$ & & Standardized B & $\mathrm{t}$ & Sig. & Standardized B & $\mathrm{t}$ & Sig. \\
\hline 3 & (Constant) & & 15,25 & 0.000 & & 29,441 & 0.000 \\
\hline & Traditionalism &,- 099 & $-10,48$ & 0.000 &,- 243 & $-26,804$ & 0.000 \\
\hline & $\begin{array}{l}\text { Orientation } \\
\text { towards the } \\
\text { success }\end{array}$ & ,078 & 8,83 & 0.000 &, 044 & 5,181 & 0.000 \\
\hline
\end{tabular}


OF PSYCHOLOGY

IN THE $21^{\text {st }}$ CENTURY Volume 7, 2013

\begin{tabular}{|c|c|c|c|c|c|c|c|}
\hline $\begin{array}{l}\text { ESS } \\
\text { round }\end{array}$ & & Standardized B & $\mathrm{t}$ & Sig. & Standardized B & $\mathrm{t}$ & Sig. \\
\hline & $\begin{array}{l}\text { Co-other } \\
\text { orientation }\end{array}$ & ,113 & 11,791 & 0.000 & ,217 & 23,496 & 0.000 \\
\hline \multirow[t]{4}{*}{4} & (Constant) & & 18,508 & 0.000 & & 31,995 & 0.000 \\
\hline & Traditionalism &,- 088 & $-9,724$ & 0.000 &,- 262 & $-30,281$ & 0.000 \\
\hline & $\begin{array}{l}\text { Orientation } \\
\text { towards the } \\
\text { success }\end{array}$ & ,053 & 6,241 & 0.000 & ,046 & 5,731 & 0.000 \\
\hline & $\begin{array}{l}\text { Co-other } \\
\text { orientation }\end{array}$ & , 108 & 11,727 & 0.000 & ,232 & 26,543 & 0.000 \\
\hline
\end{tabular}

Dependent Variable: European Union: European unification go further or gone too far
Dependent Variable: Allow many/few immigrants from poorer countries outside Europe

Weighted Least Squares Regression - Weighted by d weight * $p$ weight

Table 2. Influence of personal orientations on the citizens' activeness.

\begin{tabular}{|c|c|c|c|c|c|c|c|}
\hline $\begin{array}{l}\text { ESS } \\
\text { round }\end{array}$ & & Standardized B & $\mathrm{t}$ & Sig. & Standardized B & $\mathrm{t}$ & Sig. \\
\hline \multirow[t]{4}{*}{3} & (Constant) & & 72,263 & 0.000 & & 18,687 & 0.000 \\
\hline & Traditionalism &,- 251 & $-27,914$ & 0.000 &, 038 & 3,181 & 0.001 \\
\hline & $\begin{array}{l}\text { Orientation towards } \\
\text { the success; }\end{array}$ &, 004 & ,448 & 0.654 &,- 114 & $-10,221$ & 0.000 \\
\hline & Co-other orientation & ,240 & 26,245 & 0.000 &, 058 & 4,805 & 0.000 \\
\hline \multirow[t]{5}{*}{4} & (Constant) & & 80,017 & 0.000 & & 16,695 & 0.000 \\
\hline & Traditionalism; &,- 309 & $-36,658$ & 0.000 &, 062 & 5,222 & 0.000 \\
\hline & $\begin{array}{l}\text { Orientation towards } \\
\text { the success }\end{array}$ & ,004 &, 571 & 0.568 &,- 079 & $-7,179$ & 0.000 \\
\hline & Co-other orientation & ,259 & 30,322 & 0.000 & 051 & 4,290 & 0.000 \\
\hline & Dependent Variab & actual social-po & activenes & & \multicolumn{3}{|c|}{$\begin{array}{l}\text { Dependent Variable: passive political } \\
\text { interest }\end{array}$} \\
\hline
\end{tabular}

Weighted Least Squares Regression - Weighted by d weight * $p$ weight

In both rounds the orientation to success is also a predictor in a positive direction for the same dependent variables, with the exception of its insignificant influence on the actual social-political activeness /see Table1, Table2, Table3/. Furthermore it reveals a significantly negative relation with the passive political interest. Obviously the influence of a personality characteristic such as the orientation to success, self-realization, is directed more towards an individual realization and to a less extent to involvement in political activities; which, however, not only does not hinder but it also stimulates the openness and a positive attitude to diverse social/ethnic groups coming from poorer countries, trust in the European Parliament, positive reception of people with a different sexual orientation etc. 
Table 3. Influence of the personal orientations on the attitude towards people with a different sexual orientation; influence of the orientations on the trust in the European Parliament.

\begin{tabular}{|c|c|c|c|c|c|c|c|}
\hline $\begin{array}{l}\text { ESS } \\
\text { round }\end{array}$ & & Standardized B & $\mathrm{t}$ & Sig. & Standardized B & $\mathrm{t}$ & Sig. \\
\hline \multirow[t]{4}{*}{3} & (Constant) & & 38,204 & 0.000 & & 17,983 & 0.000 \\
\hline & Traditionalism &,- 283 & $-31,956$ & 0.000 &,- 014 & $-1,430$ & 0.153 \\
\hline & $\begin{array}{l}\text { Orientation towards } \\
\text { the success }\end{array}$ & ,070 & 8,415 & 0.000 &, 074 & 8,084 & 0.000 \\
\hline & Co-other orientation & ,282 & 31,310 & 0.000 & ,022 & 2,176 & 0.030 \\
\hline \multirow[t]{4}{*}{4} & (Constant) & & 41,568 & 0.000 & & 15,735 & 0.000 \\
\hline & Traditionalism &,- 282 & $-33,161$ & 0.000 &,- 009 & $-1,019$ & 0.308 \\
\hline & $\begin{array}{l}\text { Orientation towards } \\
\text { the success }\end{array}$ & 097 & 12,322 & 0.000 & 069 & 8,038 & 0.000 \\
\hline & Co-other orientation & ,265 & 30,726 & 0.000 & ,062 & 6,580 & 0.000 \\
\hline \multicolumn{5}{|c|}{ Dependent Variable: Gays and lesbians free to live life as they whish } & \multicolumn{3}{|c|}{$\begin{array}{l}\text { Dependent Variable: Trust in the European } \\
\text { Parliament }\end{array}$} \\
\hline
\end{tabular}

Weighted Least Squares Regression - Weighted by d weight * $p$ weight

The third factor - of the "traditionalism" is found to be negatively influencing all dependent variables /see Table1, Table2, Table3/, included in the regressive analysis for both rounds, except its positive influence on the passive interest in politics and its insignificant effect on the trust in the European Parliament /see Table1/. Apparently, despite the generally accepted positive place of tradition, an excessive respect to the rules and the others' expectations hinder the opening of the personality to more complex identifications and leads to a certain indifference and distance to the actual processes in contemporary Europe. In the regressive analysis the variable "how religious" is the subject is found to be with a significantly positive predictor effect on some attitudes, including the attitudes toward the development of Eurounification /only in 2008/, and in 2008 it's influence the acceptance of immigrants from poorer countries outside Europe is positive /Table4/; but with a significantly negative effect on the attitude towards the freedom of people with different sexual orientation in the both ESS rounds.

Table 4. Influence of religiousness on the acceptance of immigrants.

\begin{tabular}{|c|c|c|c|c|c|c|}
\hline \multirow{2}{*}{ Predictors } & \multicolumn{2}{|c|}{ Standardized B } & \multicolumn{2}{|c|}{$t$} & \multicolumn{2}{|c|}{ Sig. } \\
\hline & 2006 & 2008 & 2006 & 2008 & 2006 & 2008 \\
\hline (Constant) & & & & 68.494 & 63.949 & 0.000 \\
\hline $\begin{array}{l}\text { How religious } \\
\text { are you }\end{array}$ & 0.031 & 0.044 & 3.040 & 4.504 & 0.002 & 0.000 \\
\hline
\end{tabular}

a Dependent Variable: Allow many/few immigrants from poorer countries outside Europe

b Weighted Least Squares Regression - Weighted by d weight * p weight 
OF PSYCHOLOGY

IN THE $21^{\text {st }}$ CENTURY Volume 7, 2013

Table 5. Influence of religiousness on the attitudes to people with different sexual orientation.

\begin{tabular}{ccccccc}
\hline Predictors & \multicolumn{2}{c}{ Standardized B } & \multicolumn{2}{c}{$\mathrm{t}$} & \multicolumn{2}{c}{ Sig. } \\
\hline & 2006 & 2008 & 2006 & 2008 & 2006 & 2008 \\
\hline (Constant) & & 270,197 & 289,870 & 0.000 & 0.000 \\
How religious are you &,- 152 &,- 168 & $-18,608$ & $-21,422$ & 0.000 & 0.000 \\
\hline \multicolumn{7}{c}{ Dependent Variable: Gays and lesbians free to live life as they whish } \\
& Weighted Least Squares Regression - Weighted by d weight * $\mathrm{p}$ weight \\
\hline
\end{tabular}

In general the outcome related to the tolerance towards diversity, in this case towards people with different sexual orientation (see Table 5) cannot be estimated as unexpected since the latter is not acceptable according to religious views. Simultaneously significant and interesting are the observations on a connection and a positive influence of religiousness on the European integration in 2008 (see Table 6).

Table 6. Regression analysis of citizen's religiousness degree in ESS rounds 2006 and 2008.

\begin{tabular}{ccccccc}
\hline Predictors & \multicolumn{2}{c}{ Standardized B } & \multicolumn{2}{c}{$\mathrm{t}$} & \multicolumn{2}{c}{ Sig. } \\
\hline & 2006 & 2008 & 2006 & 2008 & 2006 & 2008 \\
\hline (Constant) & & & 123,698 & 130,942 & 0.000 & 0.000 \\
How religious are you &, 002 &, 050 &, 179 & 6,152 & 0.858 & 0.000 \\
\hline
\end{tabular}

Dependent Variable: European Union: European unification go further or gone too far Weighted Least Squares Regression - Weighted by d weight * $p$ weight

Religiousness appears to be a significant predictor related to the attitudes of the Europeans towards the influence of immigrants on the economy, the culture and the life in general in the countries where they reside. It also exerts a positive influence on the passive political interest but its impact on the active political activity of individuals is insignificant. In both rounds religiosity has a positive predictor influence on trust in EP.

A conclusion can be outlined that following the rules and avoiding active involvement in political processes exerts their influence in direction increase of social distances, as well as distance to EU processes. It may seem a paradox at first sight that a factor like following accepted norms and rules could influence in a negative manner the behaviour and involvement of citizens and their attitudes toward immigrants. It can be assumed that only a certain type of norms and rules that conservatively preserve the status quo have an actual effect and not norms and rules of behaviour in general. (There could be a relation to the political orientation of citizens as well but it has not been examinated in the recent work). In a way this demonstrates the closeness of conformity to established solid regulation and the unwillingness to accept social changes or an ethnic/racial or other diversity in the EU.

\section{Discussion}

There are no doubt that enlargement of the opportunities for mobility, contacts with representatives of various cultures and communities changes the stereotypes, enriches representations of individuals of others, as well as of themselves as persons and members of various social groups, communities, ethnic groups, nations. However, this is a slow process and the dependence of the cognitive constructs and mechanisms is in no way simple linear dependency of the change of the daily life of the individuals or social groups. Cognitive scheme's development is not a per se process, it leads to a new social regulation of the behaviour of interpersonal and inter-group level (Zografova, 2008). Maintaining multiple identifications with various social categories and/or groups makes 
individual excel the geographic, physical and psychic dimensions- attain psychic flexibility to accept the otherness, because he/she starts to represent symbiosis of various "others" by the means of involvement in the various categories. Domination of the tolerance in perceiving the others within the EU framework induces enlargement of the scope of tolerance and social representations also towards communities out of the EU. This takes place on the basis of the psychic mechanisms of development of cognitive images, models, accepting in general the others, and otherness - afterwards representations transfer to neighbouring objects. To know and to accept the multiple identifications, incl. the unrelated identities is a way social identity complexity to be attained. Brewer \& Pierce suggest that complexity correlates significantly positively with the tolerance to the external, foreign group - "both cognitive and motivational factors lead us to predict that complex social identities will be associated with reduced in-group favoritism and increased tolerance and positivity toward outgroups in general (Brewer \& Pierce, 2005, p. 431).

One decade ago, the research in the social-psychological field still used to reveal results in the direction of support of Multiculturalism (Hornsey\&Hogg, 2000) but the ESS results demonstrate that throughout the years, positive attitudes towards diversity and expression of co-otherness phenomena, have been more positively developed. As Gergen states, developing his ideas of relational existence: "All that we take to be real, true, valuable or good finds its origin in coordinated action" (Gergen, 2009, p. 31).

\section{Conclusions}

It can be argued that the answers of the investigated scientific question are not final, but the discussion on the ESS data definitely outlines an establishment of the social-psychical interrelations of personal orientations and tolerance, the broader extent of the social-political involvement and the reception of the European integration in a European collective, national and individual aspect. One of the variables that approximate by its meaning the study of attitudes towards diversity is the tolerance to immigrants. It is important to understand to what extent the developed ability to think and act as a co-other, as a co-European, regulates the manifestation of tolerance to "external" subjects, others, foreigners, and to those who come from poorer countries outside Europe. The attitude and value orientation to accept others, placing oneself in their position (co-otherness), as well as the affiliation to different communities, are determining the widening of the image of foreigners' impact on the social reality in the country.

A broader analysis of secondary ESS data, the presence of some distinctions among European countries (those that were discussed in this paper) were proved, and the general trend to perceive the immigrant as a factor with a positive influence on the culture, the economy and the life in general in the EU countries was observed (See Zografova, 2011). This trend can be used by the social researchers to build models of influence and interdependence between citizens' attitudes and the real practices and policies on a European level.

Other important conclusions have also emerged in relation to the fact that the development of the contemporary social psychic's specificities, in the form of co-otherness phenomena, together with the fact of belonging to certain communities, tend to increase the interest in politics and higher rates of participation both in the passive public sphere (keeping up with different media news and events), and in the active public sphere (work in political parties, participation in political initiatives, demonstrations, petitions and more) (ibid.). Certainly here one of the aspects of the complexity of social contexts is being discussed, depending on the national specifics and the concrete situations, the level of social-economical development and particular subgroup relations between the diverse groups found in every separate country that differ by their own presence and interrelations. The contemporary condition dynamically modulates correlations and even stable attitudes could be changed by extreme events: for instance, the actual increasing immigrant flows towards Eastern and Western Europe, as well as the refugees waves from Arab and African countries could cause negative development of interethnic relations and to deepen the cohesion within groups before the threat, either imaginary or perceived as real. (Sarrasin et al, 2012). It is precisely the time to understand and effectively implement the European politics and initiatives to affiliate the EU citizens with shared values and practices so as to multiply the perspectives of tolerance and mutual acceptance. 


\section{References}

ESS Round 4: European Social Survey Round 4 Data (2008). Data file edition 1.0. Norwegian Social Science Data Services, Norway - Data Archive and distributor of ESS data.

ESS Round 3: European Social Survey Round 3 Data (2006). Data file edition 3.2. Norwegian Social Science Data Services, Norway - Data Archive and distributor of ESS data.

Brewer, M., Pierce, K. (2005). Social Identity Complexity and Outgroup Tolerance. Personality and Social Psychology Bulletin, 31, 428-437.

Calhoun, C. (2003). Critical social theory. Kritika i humanizum, Sofia.

Eriksen, E (2005). An Emerging European Public Sphere. European Journal of Social Theory 8 (3), 341363.

Gergen, K. (2009). Relational Being. Beyond Self and Community. Oxford University Press

Hornsey, M., \& Hogg, M. (2000). Assimilation and Diversity: An Integrative Model of Subgroup Relations. Personality and Social Psychology Review, 4 (2), 143-156.

Immerfall, S., Boehnke, K. \& D. Baier, 2010. Identity. Immerfall, S., G. Therborn, (Eds.), Handbook of European Societies. Social Transformations in the 21st Century. Springer, 325-354.

Sarrasin, O., Green, E.G.T., Fasel, N., Philipps, O., Staerklé, C., \& Clémence, A. (2012). Opposition to Antiracism Laws Across Swiss Municipalities: A Multilevel Analysispops. Political Psychology, 33 (5), 659-680.

Schwartz, S. H. (2012). An Overview of the Schwartz Theory of Basic Values. Online Readings in Psychology and Culture, 2(1). http://dx.doi.org/10.9707/2307-0919.1116

Sicakkan, H. (2003). Politics, Wisdom and Diversity. Or Why I don't want to be tolerated? Norwegian Journal of Migration Research, 4, 32-44.

Sicakkan, H. (2008). Positioning the Diversity Perspective. Eurosphere Working Paper Series, 1, http://eurosphere.uib.no/knowledgebase/workingpapers.htm

Sicakkan, H., Y. Zografova, (2009). Citizens' Impact on the Articulation of European Public Sphere. Explaining Citizens' Attitudes to European Integration, Eurosphere Working Paper Series, http://eurospheres.org/ publications/workpackage-reports/

Tajfel, H. (1981). Human groups and social categories: studies in Social Psychology. Cambridge

Turner, J. (1984). Social identification and psychological group formation. Tajfel, H. (Ed.), The social dimension: European developments in Social Psychology. Cambridge

Zografova, Y. (2008). Social psychological knowledge and development of new conceptions and behaviour models. Chobanova, R. (Ed.), Demand for Knowledge in the Process of European Economic Integration, Institute of Economics, BAS, 255-264.

Zografova, Y. (2011). Widening Intercultural Representations. The Citizen's Aspect of Development of European Public Sphere. Eurosphere Online Working Paper Series http://eurosphere.uib.no/knowledgebase/ workingpapers.htm

Advised by Irena Gailiene, SMC "Scientia Educologica”, Lithuania

Received: September 22, 2013

Accepted: December 02, 2013 